\title{
Heritage-An Open Access Journal of Knowledge, Conservation, and Management of Cultural and Natural Heritage
}

\author{
Francesco Soldovieri $^{1, *(D)}$ and Nicola Masini ${ }^{2}$ (D) \\ 1 Institute for Electromagnetic Sensing of the Environment, National Research Council, Via Diocleziano, \\ 80124 Napoli, Italy \\ 2 Institute of Archaeological and Monumental Heritage, National Research Council„, C.da S. Loya, \\ 85050 Tito Scalo (PZ), Italy; n.masini@ibam.cnr.it \\ * Correspondence: soldovieri.f@irea.cnr.it; Tel.: +39-081-762-0651
}

Received: 7 May 2018; Accepted: 14 May 2018; Published: 14 May 2018

Over the last fifteen years, studies on cultural heritage $(\mathrm{CH})$ have assumed a methodological, cultural, and scientific perspective, aimed at creating an area in which to carry out frontier research to be replicated in other domains. Based on the use of technologies and methodological approaches, and stemming from other domains with the goal of connecting to the knowledge of the human past, conservation, interpretation, and management of cultural heritage, this paradigm is rapidly changing.

This awareness has made it necessary to create a "place", or meeting point, to compare and discuss different ways of interpreting, conserving, and enhancing the natural and cultural heritage, by resorting to and making advances in the ever more performing and reliable technologies, and by exploiting the potential of digital humanities and the opportunities of Big Data.

HERITAGE journal is such a place, conceived as a "cultural common place", where scientists and experts concur in giving an answer to the significant issues affecting cultural and natural heritage $(\mathrm{NH})$. This is done by looking at all the necessities related to the different phases of life-cycles regarding discovery, protection, management, fruition, and exploitation. The final aim is to increase the cultural and economic value of $\mathrm{CH}$ for an improved role in the development of the society.

HERITAGE is an international, peer-reviewed, open access journal of cultural and natural heritage science published quarterly by MDPI. It focuses on knowledge, conservation, interpretation, and management of cultural and natural heritage, by sensing technologies, novel methods, best practices, and policies.

Our ambition is to set up a journal that aims to provide a multidisciplinary vision of $\mathrm{CH}$ and $\mathrm{NH}$, by means of interdisciplinary approaches, where all the technical and non-technical aspects have to be considered and faced. This necessity is now well understood in the field of $\mathrm{CH}$ and $\mathrm{NH}$, where it is important to not only develop and assess technological and scientific tools to manage the preservation and protection, but also to increase the awareness of our society and public with respect to the social and economic value of the $\mathrm{CH}$. This last aspect has implied that HERITAGE be considered as one of the main pillars of the social sciences and humanities, which now play an increasingly important role in improving the awareness of the community on these topics and problems, and on the contribution that science and technology can provide to civil society in these new challenges for $\mathrm{CH}$ and $\mathrm{NH}$.

Therefore, HERITAGE is motivated by a visionary challenge, where the issues of the management and protection of $\mathrm{CH}$ are faced under a fully holistic approach encompassing technological and social disciplines, with the aim to present and provide 
- Solutions for protection, conservation, and recovery of archaeological and architectural heritage;

- New approaches to the study of human past, by using the most advanced technologies and scientific methods

- Information and Communication Technologies (ICT) for $\mathrm{CH}$ management (solutions to turn from sensors to really useful information for stakeholders) and fruition, by looking to the state of art solutions in this field;

- Policies and human science contributions for increasing the cultural and economic role of $\mathrm{CH}$ in the society.

Therefore, this journal represents a "cultural meeting point", where scientists and experts from different disciplines will share their knowledge and experience in view of a common aim. In this vision, the HERITAGE journal intends to fill a missing gap, since it will consider a multi-perspective and holistic approach to the $\mathrm{CH}$ and $\mathrm{NH}$ worlds, by also bridging seemingly distant disciplines.

With the inclusion of articles, reviews, perspectives, and communications, Heritage offers an appropriate format for any length or type of submission.

The journal will be organized in six subsections:

- Sensing technologies for diagnostics and the monitoring of architectural and artistic heritage;

- Innovative solutions and best practices for protection of natural heritage;

- Innovation and research in the field of conservation and recovery of archaeological and architectural heritage;

- Geoscience and earth observation technologies for heritage risk assessment and mitigation and the study of human past;

- ICT for $\mathrm{CH}$ management and Fruition;

- Policies and human science contributions with the aim of increasing the cultural and economic role of $\mathrm{CH}$ in our society.

In this way, HERITAGE has the ambition to provide knowledge and experience in real cases for a very large audience including, but not limited to: conservators and archaeologists, technological experts for sensing and diagnostics, experts in materials analysis and design, ICT experts for improved fruition and novel systems for $\mathrm{CH}$ and natural valorizations, management and protection, human science experts or cultural value, and policy makers.

In closing, on behalf of HERITAGE's editorial board, we welcome you to your new forum for sharing science, perspectives, and case studies, and for identifying new challenges in $\mathrm{CH}$ and $\mathrm{NH}$.

Conflicts of Interest: The authors declare no conflicts of interest.

(C) 2018 by the authors. Licensee MDPI, Basel, Switzerland. This article is an open access article distributed under the terms and conditions of the Creative Commons Attribution (CC BY) license (http://creativecommons.org/licenses/by/4.0/). 